\title{
PROPERTY RIGHTS ON THE INTERNET: IS A SPECIFIC INSTITUTIONAL FRAMEWORK NEEDED?
}

\author{
ERIC BROUSSEAU* \\ University of Paris X, Institut Universitaire de France, FORUM, Bâtiment K, 200 Avenue de la \\ République, F-92001 Nanterre Cedex, France
}

(Received 31 October 2002; In final form 27 November 2003)

\begin{abstract}
Digital technologies allow the implementation of more decentralized Property Rights (PR) systems as compared to those traditionally set-up by public authorities at the national level. The self-implementation of exclusive rights of use over information and the design of self-regulation by virtual communities enable agents to set-up and manage PR according to their local constraints and individual preferences. However, a decentralized system has weaknesses. It can result in conflicts and defaults of enforcement that might discourage investments. It can also induce inefficient capture of public goods and favor the development of monopolies. Implementing a last resort authority in charge of limiting and preventing these inefficiencies might result in a more efficient use of resources. Based on the principle of subsidiarity, it should supervise the behaviors of individuals and communities to prevent boundless capture of public wealth by individual interests, to solve conflicts among claims for exclusive rights of use and among local regulations, and to guarantee enforcement when exclusive rights of use are legitimate.
\end{abstract}

Keywords: Digital economics; Network regulation; Intellectual property rights; Self-regulation; Global governance; Federalism

JEL classification: $\mathrm{H} 4 ; \mathrm{K} 2 ; \mathrm{L} 4 ; \mathrm{L} 5 ; \mathrm{L} 9$

\section{DIGITAL TECHNOLOGIES AND THE CHALLENGE TO TRADITIONAL INTELLECTUAL PROPERTY RIGHTS SYSTEMS}

Like the information technologies of the past (e.g. paper, press, mechanical then magnetic recording, etc.), digital and network technologies - symbolized by the internet - are challenging existing Intellectual Property Rights (IPR) systems. First, they allow them to be bypassed, both because users of protected works of authorship or ideas can infringe the exclusive rights of use granted to owners at a lower cost than before, and because the authors or inventors can use the technology to de facto create exclusive rights of use without relying on legal tools. Second, the new technology influences the relative costs and relative economic consequences of many activities related to the production, the reproduction, or the use of information. The new technology challenges, therefore, the trade-offs on which existing IPR systems are built to solve the protection/diffusion dilemma.

Having a technology challenging the existing institutional frameworks is not new per se. The way the internet challenges IPR systems is, however, radical. Indeed, digital networks

* Tel.: (33)-01-40-97-59-22; Fax: (33)-01-40-97-59-07; E-mail: eric@ brousseau.info 
make it possible to create a fully decentralized and global IPR system based on the principle of self-governance. Thanks to the capabilities of end-to-end networks ${ }^{1}$ and of encryption; economic agents are able to design and make self-enforceable specific rules stating how any set of information - whether it is a piece of recorded music, a written document, a piece of software, a video, a picture, a data base or a set of instructions enabling the reproduction of a technical realization (e.g. a CAD data file describing a piece of material, and making it possible to pilot a computer-driven machine tool to manufacture it), etc. - can be used. They can authorize (or not) access by single individuals or by groups and can control how this information will be used. Moreover, they can make these authorizations of access and use tradable (or not) with third parties. It is technically feasible today, for instance, to encrypt pieces of recorded music and to decide whether the decryption keys will allow the user to use the encrypted material once or several times, to listen only or to copy or to redistribute it. The agent who encrypts information and distributes decryption keys designs and allocates de facto exclusive rights of use without claiming for legal recognition and protection for such rights. Moreover, since the administration of the internet is decentralized, he can potentially bypass a public regulation that would prevent him from doing so. Public authorities would be unable to prevent him from distributing his encrypted material from a server abroad.

Of course, most of the agents that produce or distribute information today continue to rely on traditional legal tools. While developing quickly, the internet remains a marginal way to exchange and distribute contents. Bandwidth is still scarce (in the last meters) and personal computers and players specialized in handling digital files are still not widely adopted by users of information services. There is no doubt, however, that the internet will become the integration platform of most information networks in the future. It will be a broadband internet connecting billions of machines able to automatically process information in various ways. Consumers and professional information services of all sorts - music, TV programs, movies, training tools, data-bases, software, etc. - will be distributed through the internet raising the question of how IPR will perform and be managed.

In any case, the present internet is already challenging some major industries, especially the music industry. Since the year 2000, the sales of CDs have been decreasing worldwide, and it is expected that the sales of music companies will be down about one third in 2004 as compared to the peak reached in 1996. Many analysts establish a link between this dramatic fall and the development of the exchanges of MP3 files on line. On the one hand, pirates make multiple copies (at virtually no cost) of the records issued by the industry. On the other hand, major music corporations try to implement technological solutions to prevent the reproduction of their material and to control the uses of their digital files. They even expressed their intention to put viruses onto their files to harm the hard disks of pirates. This is clearly a movement toward the self-delimitation and the self-enforcement of property rights (PR) by both sides of the market, which increasingly bypass the existing IPR systems and institutions.

Faced with these developments, two major attitudes have emerged. The 'conservative' one consists in 'leashing' the technology to constrain the users to enforce the existing PR, as in

\footnotetext{
${ }^{1}$ Internet is not a network per se, but a network of networks that relies on common standards and a decentralized network administration. Standardized languages allow all the information-processing devices (IPDs) connected to the internet to manage both communications among them and co-operative information handling processes. A single addressing system enables any IPD connected to the network to locate the other IPDs and to route requests and replies among them. Thanks to these two elements; all the terminal equipment connected to the internet manages communication without relying on central capabilities. Any equipment is able to locate the other terminal with which it has to manage a joint information handling process. It is also able to manage the network to guarantee the exchange of information between the two machines, and can reorganize the routing of information throughout the network if some links are broken or crowded. This capability makes the control of information flows impossible, since there is almost no obligatory gate that these flows should cross.
} 
the past (e.g. National Research Council, 2000). Lobbies push bills seeking to have recording device capabilities bounded, to be able to sell non-reproducible contents. Laws have been passed to reinforce the strength of IPR in the digital world and to make the infringement of IPR based on the use of ITs eligible for criminal suit. ${ }^{2}$ In addition, public authorities in-charge of enforcing these rights are provided with additional means to detect and punish infringers: enhanced tracking capabilities and tougher potential sentences. This is the attitude of most major IPR owners, especially the large firms in the music and motion picture industries. The 'revolutionary' school of thought claims that this is a 'lost in advance' war against all forms or piracy. Moreover, it points out that the optimal trade-off between protection and diffusion is overwhelmed by digital technologies. It is, therefore, in favor of removing most legal protection and letting the players decentrally self-organize a technologically grounded PR system. The latter's argument are well summed-up by Frischman (2001) and Elkin-Koren and Salzberger (2000).

Both schools of thought rely on strong arguments. The 'conservatives' point out that without a strong legal protection of IPR owners, potential infringers will always be able to break or bypass the technical protections implemented by the former, reducing the level of investments in inventive and creative activities. The 'revolutionaries' point out that the current IPR systems have many weaknesses that can be overcomed. Thanks to the combination of the technology with the invention capabilities of agents. In particular, economic agents should be able to finely adapt the rules framing access to information and its exchange according to its various natures (music, image, text, software, etc.) and to their preferences. However, they are both wrong in their conclusions, since they under-evaluate some fundamental weaknesses of either constructed or spontaneous order. Since the technology enables agents to bypass the constructed order, and since this order does not guarantee economic efficiency any longer, risks are high that this order will not be sustainable in the long run. On the other hand, a completely decentralized process of self-regulation could lead to inefficiencies because of the fixed cost and public good natures of information goods.

This article is, therefore, an attempt to analyze the principles that should inspire an institutional framework, which would be adapted to the settlement of IPR on the internet. We will speak of IPR in general, since the distinction among traditional categories of IPR, e.g. copyright, patents, etc., are partly overwhelmed by the rise of digital technologies. Encrypting software or a consultant report is a way to protect both the 'mother idea' and the way it is expressed or operationalized. It is, therefore, a hybrid protection as compared to the protection obtained through either patent law or copyright law (cf. Besen and Raskind, 1991).

We will first present our analytical framework - the transactional approach to PR - and define some essential notions. Second, we will develop the reasons why the technology challenges the traditional Intellectual Property institutional frameworks. We will then analyze the problems raised by self-delimitation and self-enforcement of PR in the cyberworld. This will lead us to justify the organization of a decentralized institutional framework that should be centralized on a federal basis. Such a framework would be the necessary condition to benefit from the opportunities provided by the internet and digital technologies, while avoiding the main inconsistencies and illegitimacies that threaten the cyberworld today.

\footnotetext{
${ }^{2}$ This is a part of a broader movement of expansion and systematization of protection of intangibles by IPR laws. In the case of information technologies, it started in US in 1981 with the patentability of software that led in the late 1990s to the patentability of business methods and to the criminalization of code cracking with the Digital Millennium Copyright Act (DMCA) in 1998. The European Community is also strongly strengthening IPR with, in particular, the directives on databases (1996) and copyright (1998). At the global level, Trade-Related aspects of Intellectual Property Rights (TRIPS) negotiations and agreements have been developing since the early 1980s to reinforce the enforcement of copyrights worldwide. See for instance David and Foray (2002) on this wide movement.
} 


\section{THE NEW-INSTITUTIONAL APPROACH TO PROPERTY RIGHTS}

According to Barzel (1989) and North (1990), a PR system is a set of rules and mechanisms that delimits rights of uses over economic resources and allocates them to decision makers so as to enable them to take economic actions. ${ }^{3}$ It is based, first, on a delimitation of these rights - consisting in setting the frontiers among different ways of using resources and among regimes for appropriating the output of these uses - and on a process of allocation of these rights - that are granted to individuals or groups. These operations are qualified as 'measurement' by Barzel and they generate measurement costs. Second enforcement mechanisms implement these rights of uses by excluding every untitled agent from access to the protected resources, or from capturing the output of its use. This refers to controlling access, supervising uses, granting authorization for uses, punishing unauthorized uses (either to get damages or to dissuade potential infringers), and generates enforcement costs.

In a given group - let us say a Nation - the measure and the enforcement of PR can be performed either centrally by an authority of last resort - generally the State that benefits from the monopoly of legitimate violence - or decentrally by the agents. In the former case, the Government defines for each set of economic resources the rights that can be associated with them (e.g. usus, fructus, and abusus) and maintain a register in which each of these rights on any resource is recognized for individuals or groups. Then the government sets up and operates an enforcement mechanism to expel any untitled agents from the protected use of these resources. It can be an ex-ante mechanism - e.g. a guard or an encryption mechanism that forbids access - or an ex-post mechanism that assesses violation and punishes infringers. The alternative is to have the PR self-delimited and self-enforced by agents. In the latter case, individuals (or groups) claim for exclusiveness of usage and they use available means (and in last resort violence) to have their claims enforced by third parties.

The advantages of centralization are twofold (Barzel, 1989; North, 1990; Bessy and Brousseau, 1998; Brousseau and Fares, 2000). First, it makes it possible to benefit from economies of scale and scope and from learning effects in the measurement and enforcement operations. Indeed, the central delimitation of the rights of use avoids duplication of efforts and enables individuals to specialize in the carrying out of these operations. For instance, when the legislator precisely defines the rights and duties of the owner of an apartment in a collective building, he avoids the millions of individual owners having to negotiate with each other to limit the scope of their rights of use. Moreover, the legislator can specialize himself in the analysis of problems linked to collective housing, and can therefore design better rules than those designed by unskilled owners. Second, it reduces the level of conflict since the margins of maneuver of agents are reduced. On the one hand, if a central authority limits and allocates rights of use, individual agents cannot unilaterally expand the boundaries of their rights to the detriment of the others. Second, if a central authority forces them to enforce the existing rights, incentives to infringe them are reduced since it is either ex-ante or ex-post costly to do so. Of course, what has been said depends on the assumption that the central authority is both efficient and benevolent.

The cost of centralization is twofold as well. First, it leads to inefficiencies due to inadequate adaptation of central uniform solutions to local diversified needs and preferences. If we take into account the fact that the millions apartment owners live in different buildings, the optimal

\footnotetext{
${ }^{3}$ This very fundamental understanding of property rights clearly differs from the legal notion of property rights, but the later is included in the former. Barzel and North's analysis aims at synthesizing how an institutional frame result in economic properties through the allocation of decision rights to agents and through their ability to be exchanged (to reach a more efficient use of resources). Their definition of property rights encompasses what we usually call property rights, but also the regulations that bound economic agents decision's rights, the law that establishes boundaries to the free will of agents, and the informal rules (such as social customs) that mitigates and frame individual freedom of decision, and the contracts since they allow agents to delimit the rights of use transferred to other agents.
} 
set of mutual rights and duties can differ. For instance, given the quality of the construction and the organization of space it can make sense to implement different rules about the emission of noise. Moreover, it might happen that in a building the various families share common values, and want to collectively exploit some common resources (such as a collective laundry), while in another building preferences are heterogeneous and people prefer a complete privatization of space and resources. Even if the centrally designed rule can be optional, it is obvious that it cannot take into account all the possible options. This would require unbounded computing capabilities and unlimited access to information by the central authority (e.g., it should be able to access the set of preferences of each individual). Moreover, if it was feasible, the benefit of centralization would be lost since economies of scale and learning effects would be dissipated in the design of rules adapted to any specific individual and to any particular situation. Second, centralization leads to inefficiencies, since it induces distortion between the marginal cost of limiting rights over the various uses of a resource and the marginal benefits of doing it. Indeed, delimiting and enforcing PR have a cost. Since the central authority benefits from economies of scale, scope, and learning, it cannot charge any individual for benefiting from a right to use a resource according to the marginal benefit he gets from it. Moreover, it would be tremendously costly to try to evaluate the marginal cost of any protection and the marginal individual benefit. Public and centralized PR systems are, therefore, financed by taxes (or fixed fees). These taxes (and fees) are distortive by themselves. They are also distortive since the government could dedicate many resources to delimit exclusive rights of use of little economic value; while at the same time it would under-protect access to other more valuable uses of resources.

The advantages of decentralization are the opposite. Decentralization makes it possible to finely adapt the definition of PR to the preferences of economic agents, and ensure that only the use of resources that generate a utility whose valuation is above the cost of protection will be protected. This guarantees, first, that effort will not be dedicated to designing and enforcing PR of poor economic value, second, that certain uses of some resources will remain freely available, which can raise efficiency if these resources are indivisible and renewable. ${ }^{4}$ The costs are also the opposite. Decentralization is costly for the agents because they have to bear the direct costs of measuring and enforcing the exclusive rights they claim (without benefiting from economies of scale, scope, and learning). Moreover, decentralization is the cause of many and permanent conflicts since there is no last resort authority to stop them. There can be both conflicting claims and conflicting enforcement of these (never recognized) exclusive rights of use. Agents will, therefore, over-invest in attack and defense capabilities - even to simply maintain fear equilibria - and the high level of risk will prevent part of the uses and of the trade from happening (because insurance premiums would be too high).

Decentralization also has a dynamic advantage. It facilitates individual innovation in norms, resulting in an institutional framework that is more dynamic and more able to adapt than when innovation is centralized. In particular, local norms that are particularly efficient are locally settled by individuals, and progressively adopted by the members of an emerging community (even if there is no social consensus about them). In a sense this is what happened with the norms that govern open-source software communities. The boundaries of that decentralized innovation process are obvious. First, they can result in inconsistencies. Second, since competition can be biased, efficient norms do not systematically prevail or survive (as pointed out by the literature on the diffusion of technology).

In practice, setting up a PR system, either wholly centrally or wholly decentrally, would be inefficient in the sense that the costs of setting up a complete PR system ${ }^{5}$ would be too high

\footnotetext{
${ }^{4}$ Of course this can be a problem when these resources are divisible and not renewable, but then their potential value of exchange will increase and some individuals should then build exclusion mechanisms and organize a market.

${ }^{5}$ Completeness of property rights corresponds to an ideal. It would indeed mean that any potential use of any resources would be identified and associated with a right granted to either an individual or a group. A complete PR
} 
as compared to the benefit agents would get from being able to use resources, invest in the production of production capabilities, and organize trade.

Any PR system results, therefore, from a trade-off between the advantages of centralization and decentralization. The central authority designs an incomplete PR system, and the agents decentrally complete it (or vice versa). From a normative ${ }^{6}$ point of view, this trade-off should make it possible to maximize the 'collective welfare/transaction costs' ratio; the latter notions encompassing the costs of resources dedicated for trading and for setting up the PR system (either centrally or decentrally). It would be then dependent on three main factors: the nature of the resources (which are subject or not to many different uses by many different agents), the heterogeneity of preferences of agents, and the capabilities of the central institutions. This is why the organization of PR systems differs across space, time, and given the nature of the concerned resources. This tradeoff results in a level of transaction costs (at the macro level), and a sharing of them (at the micro level), and impact on the capability of a system to generate wealth.

\section{WHAT IS NEW WITH THE INTERNET?}

To assess what is new with the internet, it is necessary to remind the reader of the logic of the existing IPR systems. In the case of information and knowledge - qualified hereafter as intangibles - the tradeoff to optimally organize a property system is highly dependent on the specific nature of information. First, its consumption is indivisible. It is, therefore, worthy of being as widely diffused as possible, although it is costly to produce. Second, it is 'naturally' complex (and costly) to exclude a third party from the use of information or knowledge since once revealed it is quite impossible to (voluntarily) remove it from the brain, which stored it, and since reproduction costs, which are much lower than production costs, decrease strongly with the development of reproduction technologies, making it easy to multiply copies whose circulation is complex to control. ${ }^{7}$ Due to the latter characteristic, only agents with capabilities of physically constraining individuals can really control the circulation and the use of information. Due to the former characteristics, it is generally acknowledged that the access and use of intangibles shall be restricted in some ways to enable their creators and potential investors to get a return on their investments and efforts, while it is recognized that this protection should be limited to favor eventual diffusion (Besen and Raskind, 1991).

system would enable almost costless transactions since agents would only have to bear the cost of meeting and agreeing on the terms of the exchange. Transaction would not be free, however, because the fixed costs of the property rights system would have already been taken into account once established, variable transaction costs would be extremely low (limited to information and negotiation costs).

It must be pointed out that a complete property system - however it is established - would be inefficient since, in the Barzel/North framework, the costs of the resources and efforts dedicated to the establishment of (tradable) rights of use over resources are balanced against the benefits of doing so: a better use of resources (because of better incentives to do so and because of the increased ability to reallocate them among agents through trade). For each resource, there is always a set of use over which the costs of defining exclusive rights would surpass the benefits from a more intensive or more efficient use. 'Minimizing transaction costs' means bounding the delimitation of rights of use up to a limit where establishing additional exclusive rights of use would not result in a more efficient use of resources.

In the case of information goods (and more generally of public goods), there is an additional reason for an 'efficient incompleteness' of PR. Since the consumption of these goods is non-rival, setting up a complete system of exclusive rights of use would deprive some economic agents of the use of these resources without increasing the use of these resources by others. This is developed in the next section.

${ }^{6}$ Indeed, in a positive perspective one should admit that selection processes are not perfect, and that public institutions are subject to capture by private interests (whether they are bureaucrats, politicians, or groups of interests). Both can prevent an efficient institutional design from emerging.

${ }^{7}$ This was true, even before the rise of ICTs. Moreover, this is true both for information and knowledge even if reproduction costs, on the one hand, teaching and learning costs, on the other hand can be high. They are much lower than creation and invention costs. 
These explain partly the organization of the traditional IPR systems (Bessy and Brousseau, 1997 ; 1998). On the one hand, the intervention of the State is required, since its power of constraint in the last resort is necessary to actually prevent individuals from using information or knowledge even if they could easily access it. However at the same time, it is recognized that too strong a protection by the State would be inefficient since it would prevent any diffusion. The traditional central (governmental) systems that 'measure' and enforce IPR provide the agents with incomplete rights, in the sense that they leave to the owners the responsibility for actually delimiting and enforcing their rights of exclusive use. The producers of information or knowledge have to delimit the piece of information or the idea on which they claim exclusivity. The government only maintains a register where it registers claims for exclusiveness of usage. The IPR owners are then responsible for detecting possible infringement and bringing infringers to court to have them sentenced to stop illegal uses or to pay damages and royalties. Since the IPR owners are bearing costs to have their rights registered and enforced, the production-diffusion dilemma is partly solved, because only the more valuable uses of information goods are actually privatized by their creators, and because the search for exclusiveness is limited by the costs of claiming and maintaining exclusivity.

From a collective point of view, this is a way to keep the costs of the PR system at a reasonable level, as well. Indeed information and knowledge can be consumed in very different ways, and can be used as inputs to produce new sets of information. Think for instance of a piece of recorded music. It can be listened by an individual, broadcasted to a wide audience, played to animate a public space, used in a motion picture, be an input into a new piece of music, etc. Centrally measuring and enforcing exclusive rights for each of the possible uses of a piece of music would mean that the central public agency - unable to value the net outcome of protection of each possible use of each piece - would manage an unbounded registry database (registering all the owners of the rights over all the potential uses), and would check any audio-visual production and any use of music to assess whether exclusive rights of use are infringed or not. Since defense of exclusive rights of use is costly, agents de facto bound their claims for exclusiveness when protection is decentralized. This results in a less complete, but less costly, IPR system.

Digital technologies have an impact on the current tradeoffs that are at the heart of the organization of IPR systems. On the one hand, they allow agents delimiting themselves at a low-cost exclusive rights of use that they can make enforceable, and whose transfer they can control at a low cost (A). On the other hand, they allow agents to bypass the traditional IPR systems and question at the same time the legitimacy and the efficiency of these systems (B).

\subsection{Private Property Rights and Private Regulations}

Digital technologies allow the implementation of a self-enforcing system of PR over information goods and services. Indeed any set of information that is codifiable in a computer can be either encrypted to control ex-ante its uses (code of access) or easily, instantaneously, and cheaply tracked to control ex-post how it has been used. Moreover, digital technologies allow the implementation at very low cost of customized conditions of exchanges over contents, since contracts governing information exchanges are made self-enforceable through digital codes. This enables agents to tailor the conditions of exchanges of intangibles to the specificities of the exchange and of the parties. While these discrimination capabilities can be used to capture monopoly rents, they can also be used to efficiently share the fixed costs of information and knowledge production among users. These lead to a more 'decentralized' setting of PR as could be deduced from the Barzel (1989) and North (1990) framework. ${ }^{8}$

\footnotetext{
${ }^{8}$ Elkin-Koren and Salzberger (2000) make a similar point, but their reasoning is based on the framework developed by Calabresi and Melamed (1972). A property rule - i.e. a rule that implements negotiable rights of use - has to be
} 
Nonetheless individual PR can be individually measured and enforced, but also collective rules - and therefore rules establishing rights of use over resources, which are a contribution to the establishment of PR - can be 'decentrally' designed and enforced. Virtual communities on the internet allow the implementation of self-regulations. As long as the size and the nature of a community allow an efficient circulation of information among its members and the implementation of credible threats (such as ostracism) to punish those who infringe its constitutive rules, a community is able to bound individual behaviors to implement collective rules. Well known by historians and anthropologists (e.g. Granovetter, 1985; Bernstein, 1992; 1996; Cooter, 1994; 1996), these self-enforced self-regulations allow communities to implement collective order either to organize collective action or to solve coordination difficulties. However, the efficiency of such mechanisms decreases when communities become larger and more diverse. Indeed, each infringer is less visible because information circulates less efficiently. Moreover, each member of the community has fewer incentives to practice retaliation since it is costly and since a member's individual action is less visible (Milgrom et al., 1990).

Internet makes an increase in the relative efficiency of community self-regulations as compared to State-driven regulations possible. First, automated-systematic tracking and facilitated exchanges of information among the members of a community increase transparency and facilitate, therefore, the detection of rule breaking. Second, digital networks allow the implementation of last resort retaliation mechanisms permitting the enforcement of self-regulations because they make it possible to expel infringers from virtual communities. Lists of subscribers and address-books - the registers - that makes it possible to include or exclude users from access to the resources used to share information - whatever they are: a website, a discussion list, a forum, etc. - allows control of entry to or expulsion from the community. Controlling it allows both the setting of the boundaries of the community and the credible threatening of potential infringers of the essential rules of the community. ${ }^{9}$

Virtual communities allow the creation of a private collective order. When dealing with IPR this means that collection of individuals can create information spaces within which they follow common rules that organize a specific management of the rights to access and use intangibles. For instance they can share common contents that are hidden to the non-members of the community. This is typically what happens in the communities of users of P2P exchange software, like Napster or Gnutella. They can also decide to follow specific rules, especially to organize incentives to contribute to the community's wealth by providing information and knowledge in order to expand the utility of the common informational resource - as in open software communities - or more simply by following the rules, which enable their users to create value or save costs - as is the case for the rules that organize the production and

preferred when bargaining costs are lower than the costs generated by a central agency in charge of ex-post assessing the damages endured by third party because of the activity of any economic agents. In the opposite case, a liability rule - whereby damages will be due to the victim in the case of losses due to the activity of a third party - is preferable. Digital technologies affect the relative costs of the alternative solutions. First, search negotiation and contract settlement costs all decrease, because it becomes possible to perform these operations on-line. Second and essentially, enforcement costs decrease strongly; thanks to encryption and access codes. Cyber-space is, therefore, more likely to be a space in which negotiable rights of uses over intangibles will be negotiated, than a world in which instances will ex-post organize compensation between information producers and information users on the basis of notarial and judicial assessment of welfare transfers among agents.

The above mentioned argument can be however contested, because the impact of ICTs on search costs is not systematically (and significantly) negative due to the strategic behaviors of parties and to the strong adverse-selection problem raised by information exchanges (Brousseau, 2001). Moreover, they do not consider that the systematic and low costs of tracking uses of information on digital networks can generate a decrease of supervision costs by a central agency that will be responsible for calculating and allocating damages ex-post.

${ }^{9}$ The credibility of such mechanism is bounded by the existing alternatives. If network externalities are strong within the community, if membership is costly - for instance, because a scarce resource (attention) has to be dedicated - if switching costs are not negligible, then those who control the access to virtual communities can exercise control and use this control to make the 'law' of the community enforceable. 
exploitation of common signals of quality (like a label or a brand name). In all these cases, free riders and infringers can be expelled from the community, which creates credible threats guaranteeing the self-enforcement of these private orders.

\subsection{The Enforceability and Legitimacy of Legal Rules in Question}

In addition to favouring the decentralized implementation of IPR, digital networks make traditional institutional frameworks less effective. Internet is $a$-territorial by nature, while public legal systems are implemented on a territorial basis. Internet's generalized interconnection ability - the end-to-end principle (see note 1) - is the basis of its ability to support a wide variety of information services. It guarantees its reliability, its efficiency, and its ability to develop as well. Internet is, therefore, necessarily the support of a worldwide connectivity that overwhelms existing regulations based on territorial legitimacy.

On the one hand, any legislation over contents can be bypassed through the internet because no governmental agency would be able to efficiently supervise the exchanges of information among citizens (or the organization that acts under their jurisdiction) and between them and foreign third parties to guarantee the enforcement of existing laws. Moreover, these exchanges can be faked, and the potential infringers of the law can use a wide set of technical means to access contents whose access would be denied by some technical means operated by the State. ${ }^{10}$ The generalized interconnectivity as well as the possibility to break codes and reciprocally to strongly encrypt them limits the ability of Governments to control network-based activities. $^{11}$

Thus, even if the internet did not challenge the legitimacy of traditional public intervention, its efficiency would be questioned. A massive bypass of state regulations is possible, since services and contents providers can locate their information-processing devices in territories where the norms that are the most in accordance with their preferences apply or even become $a$-territorial by distributing their capabilities across several jurisdictions and by hiding where various operations are actually performed. ${ }^{12}$

However, the legitimacy and the efficiency of traditional institutions are also in question. Some of the features of traditional frameworks are no longer justified because the new technological infrastructure renews the economics of information and the optimal tradeoff in institutional design.

Traditional state intervention in the design of IPR was largely justified because physical constraint (in the last resort) was the only way to really prevent untitled agents from accessing and using information. Producers of contents had to have the public authorities acting as their agents to guarantee the effectiveness of their exclusive rights of use. But this had potentially huge costs because of the amount of resources necessary to detect and assess illegal uses of protected information and knowledge. The IPR were, therefore, delimited at a very general level, without taking into account the specificities of local situations and local preferences, and without detailing all the possible uses of information sequences. By enabling agents to delimit

\footnotetext{
${ }^{10}$ Individual property rights and private regulations based on codes can also be cracked by hackers and bypassed. This is discussed in the next section.

${ }^{11}$ The governments could try to control information flows by creating 'national internets'. This would, however, result in wide losses of positive network externalities. Moreover, it would necessitate the ability to effectively forbid any uncontrolled interconnection with a foreign network to avoid creating a gateway. Moreover, having the government scanning the details of private uses of information might violate citizen's privacy and might be a threat to civil liberties.

12 This destabilizes existing legal frameworks, despite the fact that international conventions could be set up to implement common legal principles. On the one hand, inter-governmental regulations are submitted to a prisoner dilemma. To stimulate their national economies some States can decide not to ratify these conventions, thus bounding their impact by creating 'digital paradises'. On the other hand, the capacity to agree on common norms is difficult because the various legal systems result from contrasted historical and philosophical traditions, which bring us back to divergent ideologies of human nature, of social logic, or of economic activity.
} 
customized self-enforcing exclusive rights of use digital technologies remove one of the main reasons for public intervention in the setting of IPR.

Moreover, IPR were designed on a national basis because for a long time the Nation was the relevant economic space, and because an authority of last resort was available at this level only. Today the economic space is increasingly global and the same is true for the information space. In many respect it is meaningless to guarantee exclusive rights of use over information in some territories and not in others. ${ }^{13}$ Since digital networks reinforce the global character of the information space by de facto removing national borders, and since digital technologies enable to implement tools to make exclusive rights of use effective in the information itself wherever the information is used, the utility of national IPR frames decreases.

Moreover, the new technological context impacts on the efficiency of the former rules. For instance, copying copyrighted material for private purposes has been authorized in most IPR laws. This restricts de facto the rights of IPR owners to control the use of their material. It was justified because copying did not really harm their capabilities of getting revenues. Private copy was limited in scale due to the cost and the low qualities of copies. Today, the ability of digital technologies to make for free perfect copies that can be spread on a very large scale could cut most of the revenues of copyrights owners. If we admit that they have to get a return on their investments to create the intangibles, then this formerly justified restriction of copyright turns out to be totally inefficient. While this legal authorization for private copies could be removed, it would be quite hard to make the new principles enforceable by existing enforcement mechanisms at the national level for reasons already detailed.

The national level should, therefore, be bypassed either because it is not the relevant level for central intervention, or because the agents now have the possibility to decentrally manage more efficiently the problem by combining cryptographic and tracking technologies. Since the present internet is still an imperfect substitute for most traditional information services, and since many users continue to access them thanks to physical containers, existing institutional frames can be temporarily maintained. However, the development of a unified information infrastructure will turn national IPR systems into ineffective and illegitimate institutional frameworks.

\section{DOES DECENTRALIZATION MEAN NO CENTRAL CONTROL OF LAST RESORT?}

While strong arguments call for a decentralized settlement of IPR in the digital world, other arguments lead to the mitigation of this initial view. Two questions have to be discussed. First, one should wonder whether self-claims, decentralized negotiation, and self-enforcement of IPR would lead to a consistent and workable institutional environment (A). Second, one should ask whether a decentrally set-up IPR system would result in delimitation and allocation of rights of use that would result in the best possible collective outcome (B).

In answering these questions, we will discriminate between two types of arguments. Generic ones will refer to the reason why an efficient PR system cannot systematically result from selfregulation. More specific arguments can also be developed in the case of digital activities. Indeed, information and digital resources are characterized by fixed costs, non-rivalries, and

\footnotetext{
${ }^{13}$ A proof that the national anchoring of IPR is increasingly meaningless is given by the trend towards the harmonization of the protection granted by National States to authors and inventors, through the signature of international conventions aimed at harmonizing IP laws, through mutual acknowledgment of intellectual title deeds, through the establishment at the regional level of common IPR frameworks (e.g. the European patent system), and through the implementation of common IP principles in global trade agreements (e.g. TRIPS).
} 
indivisibilities that can call for specific PR regimes to solve the protection/diffusion dilemma and avoid indefinite monopolistic capture.

\subsection{The Inconsistencies of a Self-regulation of Intellectual Property Rights}

The cyber-world is a new economic space. Can a consistent and efficient system of PR emerge in that space on the sole basis of the self-delimitation and self-assignation of rights of use on information goods?

In an economic space in which there are no ex-ante legitimate exclusive rights of use, a full decentralization of the delimitation and claims for exclusive rights of use could result in overlaps (conflicting claims on the same resource) and inconsistencies (no claim for some exclusive rights of use on some resources, resulting ex-post in potential conflicts or lack of investment to develop and maintain these free resources ${ }^{14}$ ). Both would be major sources of inefficiencies in the case of rival goods. Indeed, as pointed out by Libecap (2002), if a free resource exists, implementing individual exclusive rights of use on that resource impacts on the distribution of wealth among agents. A consensual choice cannot be made since the individual preferences among possible distributions result in the type of problem of collective choice described by Condorcet (1785) and Arrow (1951). Full decentralization of PR settlement results in endless conflicts. An external arbitrage is necessary to reach an 'agreement' that is needed since incompleteness of PR impacts negatively on individual incentives to use the resource efficiently.

Would this also be the case for non-rival goods? In fact, everything depends on the centralization of the enforcement mechanism. If it is centralized - i.e. if an authority ${ }^{15}$ recognizes and enforces in the last resort the claims for exclusive use - then exclusion actually applies and one comes back to the reasoning above about rival goods, since alternative uses of information are (artificially) made rival. If there is no such central authority to enforce these claims and if agents, therefore, locally spend resources to exclude others (e.g. by encrypting their contents), then conflicting claims are not a major issue, since they result in competition on the market for the twice claimed use rights. Since information is not a rival good, claims for exclusive use compete but do not conflict. The problem is, therefore, dependent on the organization of the enforcement, but in some cases self-delimitation could require central intervention to arbiter among conflicting claims.

As stated above, the enforcement of PR relies generally on owners' efforts together with the intervention of a third party of last resort that benefits from lower costs and extended ability and credibility in punishing infringers. Indeed, the credibility of self-enforced exclusive rights of use and of self-enforced community regulations is bounded by the cost born by the infringers when detected, by the probability of this detection, and by the benefits resulting from the infringement. At least two reasons justify the intervention of a last resort authority in the internet. First, not any cryptographic system is inviolable. Code-based protection and self-enforcement are, therefore, imperfect. Second, the retaliation power of coordinators of virtual communities is obviously bounded by the ability of internet users to access alternative communities providing them with the same type of service, and by the ability of the providers of means of access to identify the users (because the only identity that is certain over the internet is that of the computers); see note 9 .

\footnotetext{
${ }^{14}$ The specialized literature usually shows that commons usually relied on precise collective rules set up by communities to efficiently exploit the commons. Exclusive and precise rights of use were therefore implemented. Here, we refer to cases where nothing has been set up. The resource is 'free' of access and conflicts will inevitably develop.

15 The authority can be a government, an inter-governmental agency, or a business alliance that would be able to deny access to contents to untitled third parts. Think, for instance, of an alliance among major music companies.
} 
This calls for an entity able to guarantee enforcement in the last resort by being able to punish infringers. Centralization is justified, first, because a last resort enforcement device that would be able to increase the costs of violating the local regulation - e.g. by excluding them from access to the cyberworld; see note 24 - would reduce enforcement costs (see Milgrom et al. 1990, Lemley, 1999, Brousseau and Fares, 2000). ${ }^{16}$ In addition, a central mechanism granted power of constraint could guarantee a minimum transparency so as to control how the protected contents are actually used. Indeed, virtual communities could organize themselves to hide the sharing of decrypted digital contents without the consent of owners. Lastly, supervision of uses implies at least a mechanism that will register claims of exclusive rights of use over information - implying a categorization of the various types of material eligible for protection - and that will check for the legitimacy and the absence of overlap among these claims. Thus, a minimum level of centralization would probably arise in a system of self-claim.

Behind the argument that a complete system of PR could be decentrally set up thanks to Information and Communication Technologies (ICTs), there is the assumption that PR settlements would cost nothing with the use of technology. This assumption, which is implicit, leads in fact to the conclusion that a complete IPR system can be centrally created as well. Lower costs of setting up PR do not mean, however, that these costs are zero. ${ }^{17}$ Encrypting digital information does not result in perfect control over its uses. Additional means have to be used to complete the incompleteness of these PR. A central (traditional) institutional system can for instance back-up the technological self-implemented protection (as in the music industry today). Economic agents could also try to decentrally reinforce technological locks by forming inter-individual agreements. These contracts would, however, necessitate an authority of last resort to guarantee their enforcement. Some sort of centralization would, therefore, be necessary. Positive measurement and enforcement costs involve PR having to be both centrally and decentrally set up to benefit from the advantage of centralization and decentralization to reduce costs.

\subsection{Why Centralization Can Support Efficiency?}

Our first line of argumentation was to question the capability of a process based on self-claim and self-enforcement to generate a consistent and workable PR system. Our second line is to question the ability of such a decentralized process to generate efficiency. The literature on private norms often refers to historical experiences (such as the medieval 'Law of Merchants') or to those norms that regulate many ethnic communities to point out the efficiency of decentralized self-regulation (cf. Granovetter,1985; Bernstein, 1992; 1996; Cooter, 1994; 1996). However, some papers also point out the limit of self-regulations (e.g. Milgrom et al., 1990). We pursue here such an analysis.

Two arguments have to be made. First, when claims or regulations conflict or overlap some mechanisms have to be designed to select (even arbitrarily and imperfectly) a solution that would seek to result in the best collective outcome. Indeed, if one admits that various stakeholders have various interests and do not have the same ability to influence the decentralized settlement of IPR - either because they have contrasted endowment or because

\footnotetext{
${ }^{16}$ Since these local regulations can be considered as participating in the general efficiency provided by the institutional framework, it is legitimate to reinforce their enforceability when necessary. The authority responsible in the last resort for the regulation of the system has, therefore, to use its credible threats to punish infringers of self-regulations. This is a common practice in the real world when the State becomes the guarantor of the enforceability of self-elaborated norms, like professional codes of conduct, by making them legally binding (see Bessy and Brousseau 1998; Brousseau and Fares 2000).

${ }^{17}$ First, data processing costs are not zero and encrypting information is costly (e.g. it takes time, generates failures, etc.). Second information-processing costs are often fallaciously assimilated to data processing costs. ICTs impact less on the first category than on the second. Indeed, the human brain that associates various types of cognitive processes is unavoidable when complex information processing occurs.
} 
they enter the game at different periods while there are path dependent phenomena (such as pre-emption) - then decentralization does not guarantee that the delimitation and allocation of PR would be fair - by considering equally the various individual interests - and efficient - by allocating uses rights so as to reach the best possible use of resources from a collective point of view. ${ }^{18}$ Second, in the case of information and knowledge, a PR system based on self-claims and self-enforcement could, in addition, lead to excessive and indefinite private capture of these public goods. It would lead to distortive capture of monopoly rents, and to the hindering of the efficient diffusion of that information.

If one admits that stakeholders can have conflicting interests, one should admit that some type of centralization is needed to compare the various possible PR systems in terms of collective efficiency so as to choose the most efficient one, whatever the efficiency criteria is. The important point here is to design a process in which the interest of the wider set of stakeholders would be taken into account. It is not a question, however, of a central planner able to centrally design the most efficient set of rules. As Hayek would argue, information constraints and the inability to aggregate individual preferences would combine to prevent the success of such initiatives. However, when conflicting claims of conflicting rules are set up, an arbitrage mechanism could explore whether or not a mutually beneficial solution could not be designed.

Historically, primitive systems of PR developed in a decentralized manner. However, it was in a logic of capture and pre-emption that did not guarantee at all either efficiency or peace. As pointed out by North (1990), economic history can be interpreted as a process of selection of more efficient systems of property rights, even if path dependency and rent seeking can prevent some societies from evolving toward more efficient PR. In this process, the State often played a central role by arbitrating among the various interests under its jurisdiction - which does not mean that it is fair, benevolent, and efficient - to help to implement PR allowing the reduction of transaction costs and the sustaining of growth.

The procedures used to setup PR on the present internet do not at all guarantee that the interest of all the stakeholders will be respected. Most of the existing norms result from a 'first claimant, first served' process. Inventors and early adopters were able to capture considerable resources. However, since the internet is becoming the basis of many social interactions involving a wide range of different types of agent, there is no legitimacy to the systematic adoption and enforcement of the norms that were designed by the first entrants, the stronger players, or the best-organized lobbies. ${ }^{19}$ Lemley (1999) and Berman (2000) point out that cyber-norms

\footnotetext{
${ }^{18}$ We are assuming a world in which it is costly to establish property rights. By definition transaction costs are positive. A reallocation of the property rights claimed by the first settlers and the norms they established could arise through (respectively) a market process and negotiations. Since transactions are costly the ex-ante allocation impacts, however, on welfare. We are in the Coasian world, not in the world of the Coase Theorem. Moreover, if the first norms' settlers were able to establish dominant positions, as it is often the case in an information economy, they will hardly agree to spontaneously reallocate rights to use resources to new entrants. An authority of last resort that would decrease the bargaining power of the incumbents will facilitate an efficient reallocation of those rights.

${ }^{19}$ While the First Come, First Served (FCFS) rule is not really damaging in the case of non-rival goods, it could strongly harm the interests of latecomers in the case of rival goods. This is for instance the case for Domain Names (which are part of the addressing system of the internet). Distinctive signals are typically information sets whose individual and collective value is dependent on exclusive uses. Latecomers can be prevented from using popular names and significant expressions captured by the first movers.

In addition, first claimants can capture the investments in reputation made by those who established and maintained quality signals in the non-digital world. This refers to a second problem. The potential externalities between the digital world and the real one. Self-claimants of exclusive rights of use and norms setters can implement rules that harm the wealth (and the incentives) of agents benefiting from rights of use outside the internet. For instance, those who develop systems that allow large-scale barter of private copies of digital contents (e.g. Napster or Gnutella), deprive the creators of content of their revenues; unless taxpayers are asked to compensate by contributing more to the funding of the production of works of art. In both cases, the created norm of free exchange affects the welfare of members of off-line communities.

Moreover, in a self-regulated environment, the FCFS principle applies to any rule over the use of resources. A last resort authority is essential to prevent inefficient capture of indivisible goods.
} 
establishers do not have to enforce any constitutional principle that would guarantee that the fundamental rights of the various stakeholders of the internet are enforced. ${ }^{20}$

Moreover, since there are interdependencies between the cyber-world and the real one, even if norms resulted from a consensus ratified by the community of cyber-citizens, nothing would guarantee their efficiency, in the sense that the interest of every stakeholder would be taken into account (Lemley, 1999). An efficient and fair distribution of resources requires processes and instances able to manage these externalities between the cyber-world and the real world.

While information becomes a good whose uses are now eligible for exclusion, it remains a non-rival and indivisible good. It is, therefore, legitimate to question the optimal level of protection within the traditional debate that balances the advantages of strong incentives to create with those of a wide diffusion (cf. Besen and Raskind, 1991). The example of freeware points out that sharing information on a very large scale maximizes the benefit of disclosure. In some cases, mandatory disclosure rules - especially if disclosure rules could be tailored to different audiences; e.g. free access to published material to students and teachers in lowincome countries - would be collectively optimal. Such rules could spontaneously emerge as happened in the open-source software communities. However, there are also many situations in which it is doubtful that they will. Since investors in the creation of digital sequences could fear to not get any return if they disclosed them, and since they can cheaply control access to them, it should result in an IPR system that would overprotect resources, in the sense that the collectivity would be deprived from the potential positive externalities of open access (externalities of diffusion, spill-overs, etc.). ${ }^{21}$ This calls for some centrality, both to select the collectively optimal system, and to compensate those who are harmed by a system in which PR are bounded as compared to what they would get if a system of unlimited rights to control uses would prevail.

There is an additional reason for bounded PR. The ability to use a specific set of information or knowledge often depends on the access to complementary information. A central system guaranteeing some fundamental rights of access to information should be able to guarantee the exploitation of these externalities.

The second essential issue is the ability of monopolies not only to capture rents but also to everlastingly hinder competition in the digital economy. On the one hand, the digital economy is often considered an economy in which competition is sustainable because the decentralized nature of digital networks and the low level of barriers to entry seem to enable any victim of the exercise of monopoly power to bypass its services providers. Contestability (Baumol et al., 1982) is, thus, supposed to be strong. On the other hand, the combination of networks effects with fixed costs make monopolies sustainable in the digital economy (cf. Shapiro and Varian, 1999; Noe and Parker, 2000). These should lead to uncertain conclusions in matter of optimal regulation by a third party. However, the combination of the capability to encrypt with the long-term viability of monopolies leads to the possibility of deterring entry for very long periods, enabling endless capture of rents and the blocking of innovation and creation in the

\footnotetext{
${ }^{20}$ A long list of examples could be given. To illustrate the problems that are arising today, let us quote three examples. Spam, or unsolicited mail, has begun to be a major concern since e-mail users spend an increasing amount of time in sorting them. Spam senders, that use up-to-date technologies to prevent their mail from being identified by e-mail software, clearly infringe the ability of e-mail users to use their bounded attention capability efficiently. Viruses also infringe the right of computer users by destroying their data and generating problems that are costly to solve. Spying systems enable any internet users - from large companies like Microsoft to individuals using appropriate software - to supervise any use on an information system made by a third party. This is of course a serious infringement to individual privacy. In the three cases, those who are inventing and spreading the related technologies re-delimit de facto the property rights in cyberspace. . . and do so without negotiating with those who stand the costs of the FCFS process.

${ }^{21}$ These arguments are developed in particular by L. Lessig in a series of conferences given in 2003 The Tragedy of the Innovation Commons?: Reconciling Private Claims with Public Interest, that should be published soon. See also: The Creative Commons, RBL, Tokyo (2003); http://www.lessig.org/content/articles/
} 
long run (by forbidding access and use of existing creations of the human mind). Such threats should lead to the binding of the encryption capabilities of agents, and the supervision of their competitive behaviors. In both cases, a last resort third party should be able to bound agents' capability to capture information and knowledge and the rents they can generate eternally.

Binding the encryption capacities of agents (e.g. mandatory registration of code keys to trustworthy third parties) would maintain a minimal level of transparency aimed at enabling supervision by some last resort authority in-charge of preventing monopolistic capture (see below). Moreover, reducing encryption capabilities would limit de facto the levels of barriers to entry and therefore the strength of monopoly power. It would guarantee the sustainability of competition in the long run. Indeed, competition is the best solution to provide agents and communities with incentives to implement efficient solutions.

It has to be pointed out that binding encryption capabilities would not be enough per se to ensure efficiency in the long run. Supervision of behavior by a third party is essential since it dissuades parties from taking anticompetitive action, without forcing agents to be totally transparent in their behaviors and information exchanges. The protection of contents (both the privacy of information exchanges and PR) leads to encryption, and it is not justified to broadcast publicly all information exchanges. It is, however, necessary to verify that information exchanges are not harmful for the collectivity; as could be the case if they were aimed at establishing collusive agreements, infringing IPR, or performing criminal activities. An independent and neutral third party in-charge of supervision is, therefore, a good solution to deter indefinite monopolistic capture, while enabling the agents to preserve privacy and to protect access to their informational contents.

\section{FEDERALISM AND CENTRALIZATION}

Digital technologies challenge the efficiency of the traditional IPR systems organized at the national level for two main reasons. First, the technology enables agents to bypass traditional legal frameworks, and to implement collective orders based either on decentralized self-claims and self-enforcement of exclusive rights of use, or on the decentralized self-organization of "virtual' communities constituted of agents agreeing to enforce the same collective rules. Second, agents are incited to bypass the national legal frames, because they play in a global space. More precisely, the internet creates a worldwide-integrated information space. It would be irrelevant to benefit from exclusive rights of use over information in some part of this information space only. Moreover, the relevant 'space' for collective regulations is only incidentally the national territory. Freed from many localization constraints thanks to transportation and communication technologies, many human activities are organized within communities - either business, linguistic, cultural, etc. - that are organized across national boundaries. Those communities sharing a common interest in being coordinated by common rules might be aggregated through alternative principles than geographical proximity. Since agents have the opportunity to implement private orders, both by individual (encryption) and collective action (subscriber lists), it should result in an institutional framework that would better fit their preferences and needs. ${ }^{22}$

\footnotetext{
${ }^{22}$ This does not mean, however, that national communities are no longer relevant. They are the appropriate space of regulation for specific categories of use and for some categories or users. The change in the institutional landscape lies in that it is no longer a hierarchical one, where centralization among various groups of interests (that can create their own specific self-regulations) is made at the Nation-State level, then at the supra-national level by inter-governmental agreements. Centralization occurs at the global level, and results from the meeting of the various self-regulated communities that can be organized within traditional national boundaries or across them. The various instances that design regulations resort to different logics (and legitimacy), so that it does not make sense to hierarchize them. There are National States, but also industry associations, various types of communities of interest, standard-setting bodies,
} 
Bypassing the traditional IPR systems should result in more efficient institutional frameworks. A decentralized and unorganized process of production of self-legitimated norms would not guarantee, however, that the resulting system of norms would be either workable, or efficient. Indeed, as the resulting communities overlap and interact, inconsistencies could result from a decentralized system of norm settlement. Moreover, self-claimed and self-enforced rights of use could infringe the rights of access and the rights of use of other stakeholders. Lastly, since digital activities refer to goods characterized by indivisibilities of consumption, self-claimed exclusive right of use could lead to inefficient capture of wealth by some individuals and groups. There are, therefore, important and numerous potential conflicts among decentralized norms setters. While decentralized negotiation could solve most of them, it is important to consider a potential institutional mechanism that would reduce the costs of settling these conflicts. Two arguments have to be taken into consideration. First, since monopoly equilibria are stable in the digital world, cyber norms setters could have little incentives to negotiate if they are involved in a competitive race, and especially if the private capture of public goods can be a strategy to win. Monopolies or coalitions (cartels) could seek to implement a sub-optimal but sustainable order. ${ }^{23}$ Second, parties are more likely to negotiate and to reach an agreement if an instance aimed at settling conflicts hangs over them. Knowing that their conflict will come to an end in a maximum delay, they are incited to negotiate. This is a well-known result of the Law and Economics literature that highlights the fact that parties negotiate 'on the stairs of the courthouse'.

A last resort conflict settlement system would, therefore, contribute to reducing the inefficiencies and weaknesses of self-regulation. It should be responsible for settling conflicts among rights claimants and norms setters by taking into account the interests of the wider possible set of stakeholders, the public nature of information, and the risks of having digital technologies used to deter competition and capture rents without time, or scale, or scope limits. This would mean of course that this central last resort authority - which will not be a government-like body, but much more a supreme court - would have to design and make enforceable constitutional principles aimed at guaranteeing some fundamental rights both to information producers and to users.

This vision does not contradict the Hayekian idea that no central authority is able to design efficient solutions, whether individual or collective, in the place of agents because of information costs and inability to aggregate individual preferences. In such a framework, individuals are free to claim for the rights they want to get and are free to self-organize communities. They measure and enforce their PR. The central device allows them (in the last resort) to solve their conflicts related to these measurement and enforcement operations, so as to reduce related costs. In addition, the central device ensures that public goods are not captured too extensively by individual interests, since there are non-rivalries in their consumption. This is very close

etc. This refers directly to the notion of 'multi-level governance' that is increasingly used in law, political sciences, and economics to address issues related to global governance.

As pointed out by Hooghe and Marks (2001), the notion of multi-level governance seeks to describe how governance has been changing in western societies. It refers to the dispersion of authority away from central government, upwards to the supra-national level, downwards to subnational jurisdictions, and sideways to public/private networks. Two bodies of economics literature have investigated these notions in particular. Neoclassical political economists and public choice theorists (e.g.Ostrom and Walker, (1997); Rosenau, (2001) insist on the idea that governance results from the establishing of dispersed self-rule on the part of diverse voluntary groups that overlap and interact in a complex way with each other, and that interact with imperfect markets and imperfect public-interest seeking institutions. Theoreticians of (fiscal) federalism have moved from studies focused primarily on formal constitutional federations, to a costs/benefits analysis of centralization $v s$. decentralization of authority (e.g. Oates, 1972; 1999)

${ }^{23}$ We are not referring to a Nirvana economy in which a first rank general equilibrium would be available. We are referring to an alternative feasible institutional framework that would result in more wealth. For instance, the current situation of a defacto low-quality standard for PC Operating Systems is sustainable, but wealth - both in terms of cost of use and quality of OS - could be enhanced if the standard was organized around Open-Source Software like LINUX, or even better quality private software like the various versions of UNIX (Sun, Apple, etc.) 
to the role assigned in National IPR systems to both the Patent Office (that solves potential conflicts ex-ante) and the courts (that solve potential conflicts ex-post).

The fact that it will 'only' solve conflict in the last resort does not mean that this 'last resort' regulation device will be able to overcome the cognitive Hayekian barriers mentioned above. While there is no means to reach first rank general equilibrium by central coordination, central institutions can be designed so as to guarantee limited bias in their decisions, wherever these biases come from: bounded rationality, information costs, opportunistic behaviors, and bureaucratic drift. It is beyond the scope of this article to discuss these issues, but political philosophy and the theory of constitutional design provide us with tools to think about institutional design (Voigt, 2003). First, checks and balances can be organized within an institutional framework to avoid indefinite capture by individual interests, and to force various stakeholders to self-control, for fear of control and sanctions by other stakeholders. Second, democratic control over key components of the institutional system should also prevent capture, and help to delimit and protect essential stakeholders' rights. These fundamental rights should not be delimited ex-ante, but through the progressive elaboration of jurisprudence (and on the basis of the existing internationally recognized principles such as the Universal Declaration of Human Rights).

The preferable ways to implement these principles in the institutional framework that will govern the global information infrastructure are clearly to be discussed. While it should be recognized that it would be impossible to design ex-nihilo an optimal set of institutions, it should be recognized that a central institution is needed and it should be dedicated for solving conflicts; while of course this will lead it to design rules by setting precedents; it should be designed so as to avoid its worst possible bias, and so as to be able to evolve thanks to learning effects (according to the 'remediability' principle advocated by Williamson, 1996). These arguments do not rely on the assumption that it would be feasible to implement a benevolent and efficient global government. It is recognized that this authority would not lead to a first best outcome (which is incidentally purely theoretical). They are based on the idea that the intervention of a central institution in the measurement and enforcement of PR is useful to complete the decentralized setting of IPR. This was recognized at the Nation-State level, but given the scope of information activities now, global, centralization can no longer be organized at that level. The last resort authority could however emerge from several processes. It could emanate directly from the private norm setters (that would delegate arbitration capabilities to it), or it could result from inter-governmental agreements (its authority being imposed on norm setters), or it could be the consequence of any hybrid process of implementation.

Beyond its logical justification, the implementation of regulation in the last resort is made possible by the necessity to centrally manage the addressing system of the internet. ${ }^{24}$ The

\footnotetext{
${ }^{24}$ End-to-end connectivity (see note 1 ) is guaranteed by a single addressing system that enables any IPD connected to the network to jointly manage information with other machines connected to the network. On the Internet, the addressing system is made of two layers. First, a numerical address is allocated to each of the IPDs connected to the network: the Internet Protocol Number. The IP Numbers are machine only readable addresses. Second, a 'userfriendly' addressing system - the Domain Name System (DNS) - is implemented to allow internet users to express their request in a language that is closer to natural language. The root of the DNS establishes the correspondence between Domain Names and IP addresses. Without this unique system, network operators would be necessary to route the requests among IPDs connected to the internet and would, therefore, control information and communication flows. The authority in-charge in the last resort of the management of the addressing system has to be alone in maintaining its consistency. It has the exclusive right to grant IP addresses and Domain Names. It is, therefore, able to deny granting such addresses to the machine owners or to the producers of contents (and more generally to users) that would not enforce the principles that this authority would be in-charge of implementing. This power of exclusion from the internet allows the authority responsible for the addressing system to be the authority of last resort for the regulation of the internet, and therefore for the implementation of IPR in the digital world.

Today, (Internet Corporation for Assigned Names and Numbers; http://www.icann.com/) ICANN is the organization in charge of the addressing system. It is a non-profit organization incorporated in US that was set up in 1998. It is responsible for distributing IP numbers and Domain Names under a delegation contract with the US Government
} 
mastering of the management of the addressing system by the entity that would be responsible for the regulation in the last resort will allow this entity to dispose of the means of its assignment. Indeed, it would enable it to dispose of a credible threat of excluding agents from access to the cyber-world that it could use to have its decisions and regulations respected. In turn, only a well designed and democratically controlled entity should be allowed to control the system of inclusion/expulsion from the internet.

\section{Acknowledgements}

This paper benefited from fruitful discussions with Jean-Michel Cornu (FING) and Daniel Kaplan (FING \& ISOC) and from comments by three anonymous referees of this journal. A draft version of a wider paper (Internet Regulation: Does Self-Regulation Require an Institutional Framework?) led Bruno Chaves (ATOM), Nicolas Curien (CNAM), Godefroy Dang N'Guyen (ENST-B), Mhand Fares (INRA), Didier Lebrun (ISOC), Hervé Nabarette (ATOM), Lee Davis (CBS), and Birgitte Andersen (Birkbeck - University of London) to make useful suggestions. I warmly thank them all. Usual caveats apply. The article was partly re-written when the author was a fellow at the International Centre for Economic Research (ICER), Turin Italy.

\section{References}

Arrow, K.J. (1951) Alternative Approaches to the Theory of Choice in Risk-Taking Situation. Econometrica, 17, 404-437.

Barzel, Y. (1989) Economic Analysis of Property Rights. Cambridge: Cambridge University Press.

Baumol, W.J., Panzar, J.C. and Willig, R.D. (1982) Contestable Markets and the Theory of Industry Structure. San Diego, CA: Harcourt Brace Jovanovich.

Berman, P.S. (2000) Cyber-space and the State Action Debate: The Cultural Value of Applying Constitutional Norms to 'Private Regulation'. University of Colorado Law Review, 7(4), 1263-1310.

Bernstein, L. (1992) Opting Out of the Legal System: Extra Legal Contractual Relations in the Diamond Industry. Journal of Legal Studies, 21, 115-157.

Bernstein, L. (1996) Merchant Law in a Merchant Court: Rethinking the Code's Search for Immanent Business Norms. University Pennsylvania Law Review, 144(5), 1765-1821.

Besen, S. and Raskind, L. (1991) An Introduction to the Law and Economics of Intellectual Property. Journal of Economic Perspectives, 5, 3-27.

Bessy, C. and Brousseau, E. (1997) The Governance of Intellectual Property Rights: Patents and Copyrights in France and in the US, Mimeo. Inaugural Conference for The International Society for New Institutional Economics, The Present and Future of the New Institutional Economics, September 19-21, Washington University, St. Louis, MO, USA.

Bessy, C. and Brousseau, E. (1998) Technology Licensing Contracts: Features and Diversity. International Review of Law and Economics, 18, 451-489.

Brousseau, E. (2001) Internet Regulation: Does Self-Regulation Require an Institutional Framework? Vth Annual Conference of the International Society for New Institutional Economics (ISNIE), Berkeley, CA, USA, September 13-15.

Brousseau, E. and Fares, M. (2000) The Incomplete Contract Theory and the New-Institutional Economics Approaches to Contracts: Substitutes or Complements?. In Ménard, C. (ed.) Institutions, Contracts, Organizations, Perspectives from New-Institutional Economics. Cheltenham: Edward Elgar Publications, pp. 399-421.

Calabresi, G. and Melamed, D. (1972) Property Rules, Liability Rules and Inalienability: One View of the Cathedral. Harvard Law Review, 85, 1089-1129.

Condorcet, J.A.N. (1785) Essai sur l'Application de l'Analyse à la Probabilité des Décisions Rendues à la Majortié des Voix, Electronic ed. (1995): http://gallica.bnf.fr/scripts/ConsultationTout.exe?E=0\&O=N041718

Cooter, R.D. (1994) Structural Adjudication and the New Law Merchant: A Model of Decentralized Law. International Review of Law and Economics, 14, 215-231.

Cooter, R.D. (1996) Decentralized Law for a Complex Economy: The Structural Approach to Adjudicating for the New Law Merchant. University of Pennsylvania Law Review, 1643-1696.

(Department of Commerce); which obviously raises essential political issues due to the potential impact of ICANN over the management of content over the internet. 
David, P.A. and Foray, D. (2002) Economic Fundamentals of the Knowledge Society. Working Paper, Stanford University, CA, Department of Economics, 2002-3.

Elkin-Koren, N. and Salzberger, E.M. (2000) The Economic Analysis of Cyber-space: Challenges Posed by Cyberspace to Legal Theory and Legal Rules. International Review of Law and Economics, 19, 553-582.

Frischmann, B.M. (2001) Privatization and Commercialization of the Internet: Rethinking Market Intervention into Government and Government Intervention into the Market. Columbia Science and Technology Law Review, Vol. II (2000-2001). Available in: http://www.stlr.org/html/archive/

Granovetter, M. (1985) Economic Action and Social Structure: The Problem of Embeddedness. American Journal of Sociology, 91(3) (November), 481-510.

Hooghe, L. and Marks, G. (2001) Types of Multi-Level Governance. European Integration online Papers (EIoP), 2001, Vol. 5. Available in: http://econpapers.hhs.se/article/erpeiopxx/p0071.htm

Lemley, M. (1999) The Law and Economics of Internet Norms. Working Paper, University of California at Berkeley, CA.

Libecap, G.D. (2002) A Transactions Costs Approach to the Analysis of Property Rights. In Brousseau, E. and Glachant, J.-M. (eds) The Economics of Contracts: Theories and Applications. Cambridge: Cambridge University Press.

Milgrom, P., North, D. and Weingast, B. (1990) The Role of Institutions in the Revival of Trade: The Law Merchant, Private Judges, and the Champagne Fairs. Economics-and-Politics, 2(1), 1-23.

National Research Council (2000) The Digital Dilemma, Intellectual Property in the Information Age. Washington, D.C.: National Academy Press.

Noe, T.H. and Parker, G. (2000) Winner Take All: Competition, Strategy, and the Structure of Returns in the Internet Economy. Mimeo, Tulane University, November.

North, D.C. (1990) Institutions, Institutional Change and Economic Performance. Cambridge: Cambridge University Press.

Oates, W.E. (1972) Fiscal Federalism. New York: Harcourt Brace Jovanovich.

Oates, W.E. (1999) An Essay on Fiscal Federalism. Journal of Economic Literature, 37, 1120-1149.

Ostrom, E. and Walker, J. (1997) Neither Markets nor States: Linking Transformation Processes Collective Action Arenas. In Mueller, D.C. (ed.) Perspectives on Public Choice: A Handbook. Cambridge: Cambridge University Press, pp. 35-72.

Rosenau, J.N. (2004) Strong Demand, Huge Supply: Governance in an Emerging Epoch. In Bache, I. and Flinders, M. (eds), Multi-Level Governance, Oxford: Oxford University Press.

Shapiro, C. and Varian, H.R. (1999) Information and Rules. Cambridge, MA: Harvard Business School Press.

Voigt, S. (ed.) (2003) Constitutional Political Economy, The International Library of Critical Writings in Economics Series, Vol. 166. Cheltenham: Edward Elgar.

Williamson, O.E. (1996) The Mechanisms of Governance. Oxford: Oxford University Press. 
